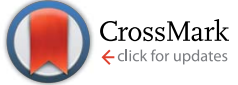

Cite this: RSC Adv., 2017, 7, 11394
Received 25th October 2016 Accepted 30th January 2017

DOI: $10.1039 / \mathrm{c} 6 \mathrm{ra} 25805 \mathrm{k}$

rsc.li/rsc-advances

\section{Use of fermented glutinous rice as a natural enzyme cocktail for improving dough quality and bread staling}

\author{
Lu Huang, ${ }^{a}$ Xiaohong Chen, ${ }^{\text {a }}$ Xin Rui, ${ }^{a}$ Wei Li, ${ }^{a}$ Teng Li, ${ }^{b}$ Xiao Xu ${ }^{a}$ \\ and Mingsheng Dong*a
}

\begin{abstract}
Solid-state fermentation of glutinous rice by Rhizopus oryzae (rice wine or Jiu-niang in Chinese) is a traditional Chinese food as well as a natural enzyme cocktail with the potential to be used in bread making. The objective of this work was for the first time to study the enzyme activities of Jiu-niang and its effect on dough quality and bread staling. The results showed that the principal enzymes in Jiu-niang were amylase, protease and lipase. The Jiu-niang enzyme cocktail significantly improved the volume, texture, and shelf life of wheat breads. The use of an optimal enzyme concentration (addition of Jiu-niang at $10 \%$ on flour basis) increased specific volume (19\%), reduced crumb hardness $(50 \%)$, and reduced moisture migration rate and bread staling rate. Using low-field nuclear magnetic resonance (LF-NMR) analysis, proton mobility and starch retrogradation of Jiu-niang bread during storage were determined and discussed. These results indicated that Jiu-niang could be used as a natural quality improver for bread making.
\end{abstract}

\section{Introduction}

Bread staling is a very complex physico-chemical phenomenon which has been studied for years and still needs to be resolved. During the storage time, bread gradually becomes harder, loses its aroma and moisture. The mechanisms of staling have been excessively investigated by many researchers. ${ }^{1-3}$ Many of them considered that starch retrogradation is only part of the reason for the changes in bread properties during storage. Water plays an important role in the staling of bread, both at a macroscopic level, migrating from bread crumb to crust but also at a molecular level, influencing the redistribution of protons and affecting the molecular dynamics of water. ${ }^{4,5}$ When retrogradation of amylopectin occurs, water changes the original location and is incorporated in crystals of retrograded amylopectin or migrates from gluten to starch causing the loss of plasticity of bread crumb and finally reduces molecular mobility. ${ }^{6-8}$ Water is redistributed among bread domains, leading to crumb hardening during storage. ${ }^{9}$ Nowadays, some additives such as enzymes and emulsifiers are applied in bread baking to improve the quality of bread. Previous studies have reported that application of amylase in bread making has a significant effect on bread anti-staling and improves the elasticity of bread

${ }^{a}$ College of Food Science and Technology, Nanjing Agricultural University, Nanjing, Jiangsu 210095, P. R. China. E-mail: dongms@njau.edu.cn; Fax: +86 25 84399090; Tel: +862584396989

${ }^{b}$ Institute of Innovation Research, Shanghai Niumag Corporation, Shanghai, P. R. China crumb. $^{10,11}$ Moreover, bread supplemented with amylase decreased the firmness of bread, increased fragrant aroma owing to Maillard reactions, improved bread loaf volume and retarded starch retrogradation., ${ }^{3,11,12}$ The anti-staling mechanisms or modes of action of amylases were different. The efficiency of anti-staling of endo-acting amylases can be attributed to their effects on weakening the starch networks by hydrolyzing the internal bonds of starch polymers. ${ }^{3}$ For exo-acting amylases, the mechanism of action is due to the degradation of the outer amylopectin branches so that amylopectin recrystallisation can be controlled. Addition of amylase in bread production is quite popular since the enzyme activity is regularly very low in wheat flour. ${ }^{13}$

Sweet fermented glutinous rice (Jiu-niang) is a traditional Chinese food prepared by fermentation of steamed glutinous rice with the starter which is composed of moulds. ${ }^{14,15}$ Jiu-niang has sweet flavor and rich nutrition which is widely accepted and is recognized as one of the most famous traditional solid-state fermentation foods in China. The principal strain in the starter is Rhizopus oryzae (determined by strain identification). Rhizopus oryzae has the ability to produce different enzymes in large quantities such as amylase, protease and lipase. The strain secretes amylase to degrade the starch molecule into fermentable sugars and non fermentable sugars. Sugars that microorganism cannot use are remained in the system to form the typical sweet aroma. Meanwhile, proteins are hydrolyzed into amino acids by protease which contributes to nutrients of Jiuniang. Furthermore, Jiu-niang is widely known by Chinese people for promoting digestion, relieving fatigue, stimulating 
blood circulation and reducing fat accumulation in blood vessels. Traditional Chinese medicinal herbs are often soaked in Jiu-niang in order to improve their efficacy. Jiu-niang is rich in amino acids, oligosaccharides and microelements which will enhance nutrition values and sweet flavor of bakery products. ${ }^{16}$

Steamed bread is a kind of steamed wheat-based food which represents $40 \%$ of the wheat consumption in China. ${ }^{17}$ Jiu-niang has been used as a quality improver in steamed bread making mainly for textural and sensory properties amelioration. Dough treated by Jiu-niang generates special flavor substances and offers sweet sensations of steamed bread. However, to the best of our knowledge, the application of Jiu-niang in bakery products has not been reported. The enzyme cocktail produced by Rhizopus oryzae is served as natural additive in dough fermentation which is beneficial to health. Jiu-niang is an extremely rich system including various kinds of enzymes which may improve bread quality and retard the staling during the storage. In this study, the effect of enzymes of Jiu-niang on bread quality will be investigated. Changes of carbohydrates and proteins during dough fermentation, as well as moisture migration, bread texture and proton distribution of bread with and without Jiu-niang supplemented during storage will be discussed.

\section{Materials and methods}

\subsection{Materials}

Wheat flour was obtained from Dachengliangyou Co., LTD (Shanghai, China). The wheat flour (given by the company) contains: $18 \%$ proteins, $2 \%$ lipids, $24 \%$ moisture and $17 \%$ energy. The starter was purchased from cereals, oil and food Co., LTD (Suzhou, China). The starter was a kind of Chinese traditional starter which was composed of Rhizopus oryzae.

\subsection{Preparation of Jiu-niang}

Jiu-niang preparation was started by washing and soaking of $1000 \mathrm{~g}$ glutinous rice in water for $10 \mathrm{~h}$. Then, the glutinous rice was steamed in the electric steamer (SUPOR Z12YN6-G2, SUPOR Electrical Equipments, Zhejiang, China) for $30 \mathrm{~min}$. The fermentation starter was subsequently added with glutinous rice : starter ratio of $99: 1(\mathrm{w} / \mathrm{w})$ after the glutinous rice cooled down to 30 to $35^{\circ} \mathrm{C}$. The glutinous rice was stored in a container and fermented at $30{ }^{\circ} \mathrm{C}, 90 \%$ relative humidity for $36 \mathrm{~h}$. The fermented glutinous rice was filtrated to obtain the filtrate.

\subsection{Preparation of dough and bread}

The basic dough recipe was composed of $500 \mathrm{~g}$ of wheat flour, $220 \mathrm{~g}$ of water for the control sample, $40 \mathrm{~g}$ of egg, $90 \mathrm{~g}$ of sugar, $5 \mathrm{~g}$ of salt and $6 \mathrm{~g}$ of yeast. For the Jiu-niang dough preparation, the addition of Jiu-niang varied from $5 \%$ to $20 \%$ on flour basis. Sugar, salt and egg were firstly added and mixed 2 min using a mixer (B25, HENGLIAN Mechanical Equipments, Guangdong, China), and followed by the addition of the rest of ingredients and mixed for $30 \mathrm{~min}$. The formed dough was then divided into pieces $(60 \mathrm{~g})$, molded and rounded before the fermentation was carried out at $32{ }^{\circ} \mathrm{C}$ for $2 \mathrm{~h}$ with a relative humidity of $82 \%$. Baking was conducted in an automatic thermostatic oven
(YXD-60, XINNANG Electric Equipments, Guangzhou, China) with the condition as follows: top temperature of $190{ }^{\circ} \mathrm{C}$, bottom temperature of $200{ }^{\circ} \mathrm{C}, 12 \mathrm{~min}$. Prior to further analyses, the breads were cooled down to room temperature and then packaged in hermetic plastic bags and stored in a temperature controlled incubator (LHS-150SC, YIHENG Scientific Instruments, Shanghai, China) at $25{ }^{\circ} \mathrm{C}$ for 7 days.

\subsection{Enzyme assays}

Amylase activity in Jiu-niang was determined according to the method of Tribst \& Cristianini (2012) with slight modifications. ${ }^{18}$ For the determination of $\alpha$-amylase activity, $1 \mathrm{~mL}$ Jiuniang and $1 \mathrm{~mL}$ soluble starch solution (1\%) was mixed and incubated at $40{ }^{\circ} \mathrm{C}$ for $10 \mathrm{~min}$. The reaction was stopped by adding $2 \mathrm{~mL}$ 3,5-dinitrosalicylic acid solution and heating in boiling water for $10 \mathrm{~min}$. The mixture was diluted with distilled water to $25 \mathrm{~mL}$. One unit of enzyme activity was defined as the amount of enzyme catalyzing to the release of $1 \mathrm{mg}$ maltose per minute at $\mathrm{pH} 5.6$ at $40{ }^{\circ} \mathrm{C}$.

Protease activity of Jiu-niang was conducted by the hydrolysis of $1 \%$ casein at $40{ }^{\circ} \mathrm{C}$ for 10 min with the Folin method. ${ }^{19} 1 \mathrm{~mL}$ Jiu-niang was incubated with $1 \mathrm{~mL}$ substrate solution for $10 \mathrm{~min} .2 \mathrm{~mL}$ trichloroacetic acid was added in order to stop the reaction. The mixture was centrifuged for $8 \mathrm{~min}$ at $5000 \mathrm{rpm}$. After the centrifugation, $5 \mathrm{~mL} \mathrm{NaCO}_{3}(0.5 \mathrm{M})$ and $1 \mathrm{~mL}$ FolinCiocalteu reagent were added into $1 \mathrm{~mL}$ supernatant. The enzyme activity was defined as the amount of enzyme catalyzing the release of $1 \mu \mathrm{g}$ tyrosine at $40{ }^{\circ} \mathrm{C}, \mathrm{pH} 3.0$, for $1 \mathrm{~min}$.

Lipase activity was measured by the method of olive oil hydrolysis. ${ }^{20}$ The amount of fatty acids was determinate by titration with $0.05 \mathrm{M} \mathrm{NaOH}$. The enzyme activity was defined as the amount of enzyme catalyzing the release of $1 \mu \mathrm{mol}$ fatty acids at $40{ }^{\circ} \mathrm{C}$.

\subsection{Changes of carbohydrates and proteins}

Agilent 1100 high performance liquid chromatography (HPLC) equipped with the COSMOSIL Sugar-D Packed Column (Tosoh Corporation, Tokyo, Japan) was used to detect the changes of carbohydrates during the fermentation of dough. $1 \mathrm{~g}$ of dough was mixed with $20 \mathrm{~mL}$ distilled water and the mixture was agitated on a magnetic stirrer for $25 \mathrm{~min}$ at room temperature and centrifuged at $10000 \mathrm{rpm}$ for $10 \mathrm{~min}$. The supernatant was eluted using $75 \%$ acetonitrile aqueous solution at a flow rate of $0.7 \mathrm{~mL} \mathrm{~min}^{-1}$ and then monitored by an evaporative lightscattering detector.

The protein changes of doughs were analyzed by sodium dodecyl sulfate polyacrylamide gel electrophoresis (SDS-PAGE), using $4 \%$ stacking gel and $12 \%$ separating gel. ${ }^{21}$ The gels were run in a Miniprotein 3 unit (Bio-Rad Laboratories, Hercules, CA, USA) at $60 \mathrm{~V}$ for $30 \mathrm{~min}$, and followed by $120 \mathrm{~V}$ for $90 \mathrm{~min}$. Gels were then scanned by Image Scanner III (GE Healthcare Biosciences, Uppsala, Sweden).

\subsection{Physical properties of bread}

Specific volume of bread was determined by rapeseed displacement method. ${ }^{22}$ Crust color was measured at the 
surface of bread by a chroma meter (CR-400, Konica Minolta, Osaka, Japan). Reducing sugar content of bread was measured using 3,5-dinitrosalicylic acid. $2.5 \mathrm{~g}$ of bread was weighed and $150 \mathrm{~mL}$ distilled water was added. The mixture was incubated at $50{ }^{\circ} \mathrm{C}$ for $20 \mathrm{~min}$. The filtrate was then collected and diluted with water to $250 \mathrm{~mL}$. The solution of reducing sugar was reacted with 3,5-dinitrosalicylic acid in boiling water for $5 \mathrm{~min}$. The absorbance of mixture was then measured at $540 \mathrm{~nm}$ by a spectrophotometer (Alpha-1101m, PUYUAN Instruments, Shanghai, China).

\subsection{Moisture migration rate}

$2 \mathrm{~g}$ of bread crumb (crust) was weighed and placed in the oven (BAO-80A, SRIK Instruments, Shanghai, China) for drying at $101{ }^{\circ} \mathrm{C}$ until constant weight. Moisture migration rate was defined as the moisture of crumb (crust) compared to the interval days between two measurements.

\subsection{Crumb texture analysis}

Texture profiles were measured by an Analyzer TA.XT Plus (Stable Micro Systems, Surrey, UK) with a cylindrical probe of $50 \mathrm{~mm}$ diameter (P50). ${ }^{23}$ The bread crumb cube was cut into a cube with $2 \mathrm{~cm} \times 2 \mathrm{~cm} \times 2 \mathrm{~cm}$. The rate of the probe was set at $1 \mathrm{~mm} \mathrm{~s}^{-1}$ and the sample bread was then compressed to $50 \%$ of the original height.

\subsection{Low-field nuclear magnetic resonance (LF-NMR)}

A low-field nuclear magnetic resonance $(21.3 \mathrm{MHz})$ spectrometer (NMI20, NIUMAG corporation, Shanghai, China) was used for determination of the proton distribution in the bread crumb. A magnetic field strength of $0.5 \mathrm{~T}$ was applied. $T_{2}$ relaxation times were detected with the Carr-Purcell-MeiboomGill (CPMG) pulse sequence. The $90^{\circ}$ pulse length was set as $7.50 \mu \mathrm{s}$ whereas the $180^{\circ}$ pulse length was set as $14.80 \mu \mathrm{s}$. Time between $90^{\circ}$ and $180^{\circ}$ pulse was $100 \mu \mathrm{s}$. Measurements were performed under a recycle delay of $2 \mathrm{~s}$ and 5000 data points. For the CPMG sequence, 32 scans were used to improve the signalto-noise ratio. MultiExp Inv Analysis software (provided by NIUMAG corporation) was used to transform the LF-NMR data to different distributions of relaxation times. For each test, the bread crumb $(2 \mathrm{~g})$ was placed in the NMR tube $(25 \mathrm{~mm}$ inner diameter) and compressed using a glass plunger. The bread crumb was measured with LF-NMR during the storage time.

\subsection{Statistical analysis}

Statistical analysis was carried out with SPSS version 21.0. A one-way-analysis of variance (ANOVA) and Duncan's multiple comparison tests were used to determine the significant differences at a level of 0.05 . The main and interactive effects of Jiu-niang concentration and storage time on hardness, springiness and cohesiveness were evaluated using a mixed-model ANOVA, where the measured variables were set as dependent variables, Jiu-niang concentration, storage time and Jiu-niang concentration $\times$ storage time as fixed effects, and replicate as random effect.

\section{Results and discussion}

\subsection{Changes of carbohydrates and proteins during dough fermentation}

Fig. 1 contains the changes of protein profiles during the fermentation process by using SDS-PAGE. Wheat gluten is a main element which will determine water absorption capacity and viscoelasticity of dough. It is composed of gliadins (50$60 \%$ ) and glutenins (40-50\%). The protein bands obtained ranged from molecular weight of $30 \mathrm{kDa}$ to $80 \mathrm{kDa}$ were probably corresponded to gliadins. ${ }^{24}$ Glutenins confer strength and elasticity of dough and possess a higher molecular weight $(>100$ $\mathrm{kDa}$ ). For the control dough, the bands have no obvious changes before and after fermentation. In case of the fermented Jiuniang dough, the intensity of some large-sized proteins bands were reduced $(>130 \mathrm{kDa})$ and a new protein band was observed ( $\sim 120 \mathrm{kDa})$. Degradation of large-sized proteins during dough fermentation might be due to the action of protease. Therefore, the addition of Jiu-niang should not be excessive, otherwise the network of wheat gluten will be weakened.

HPLC was used for the analysis of carbohydrates changes of dough during fermentation. One principal peak with the retention time of $10.0 \mathrm{~min}$ (data not shown) was observed for the dough without Jiu-niang added (Fig. 2a). For the Jiu-niang

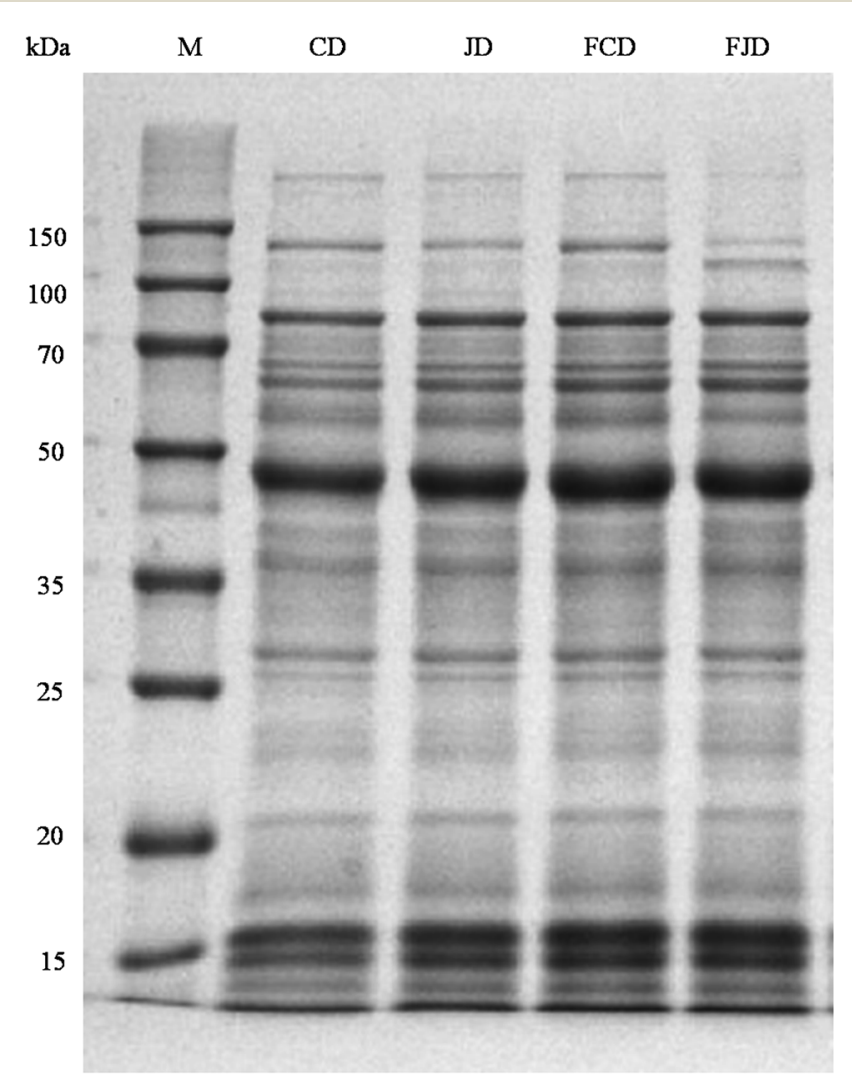

Fig. 1 SDS-PAGE electropherogram of the control and Jiu-niang doughs before and after fermentation. Lane 1: molecular weight maker $(M)$, lane 2: control dough (CD), lane 3: Jiu-niang dough (JD), lane 4: fermented control dough (FCD), lane 5: fermented Jiu-niang dough (FJD). 

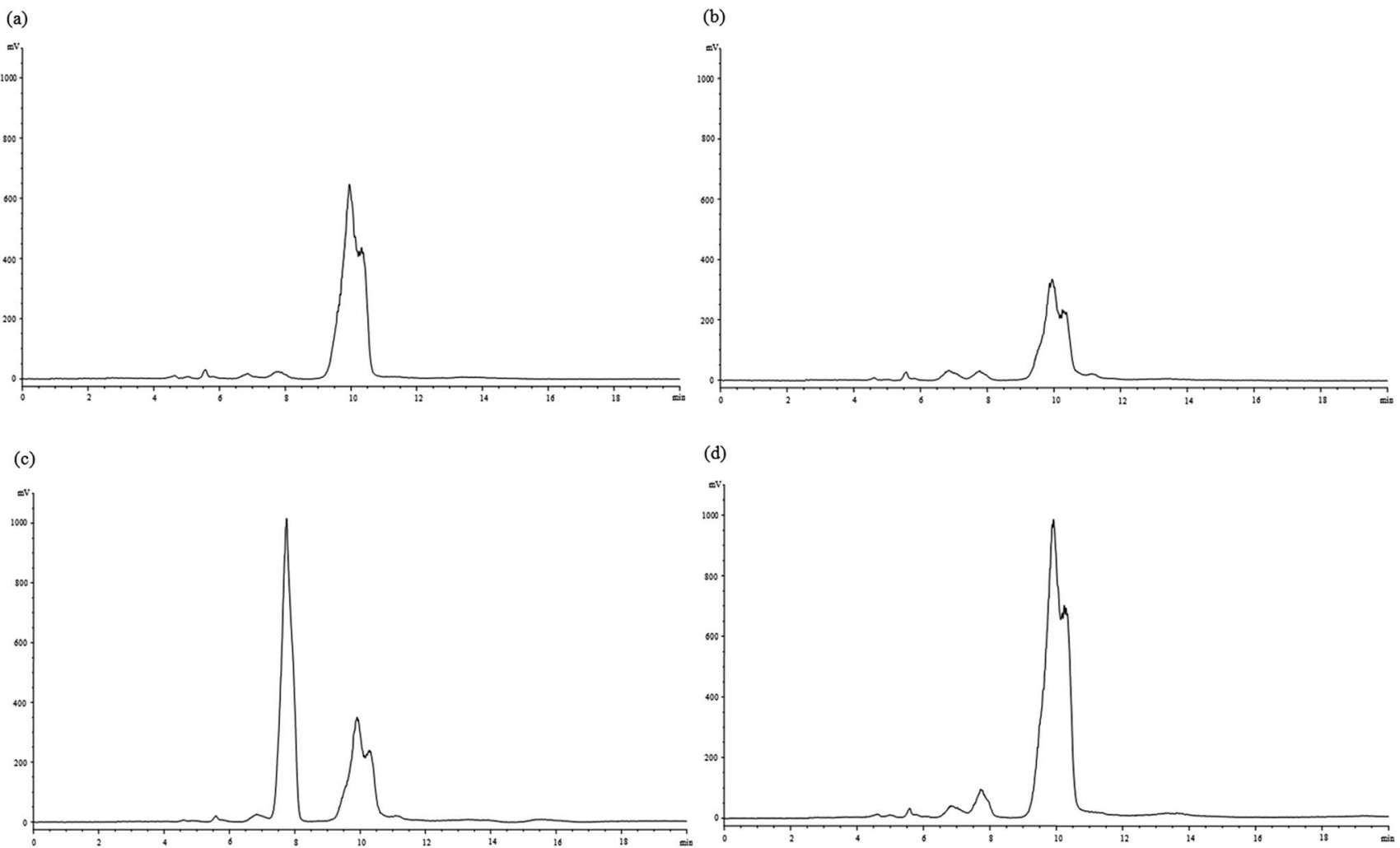

Fig. 2 HPLC chromatogram of monosaccharides and oligosaccharides of (a) control dough (CD), (b) fermented control dough (FCD), (c) Jiuniang dough (JD) and (d) fermented Jiu-niang dough (FJD).

dough, there was another major peak appearing with the retention time of $7.8 \mathrm{~min}$ (Fig. 2c). According to the curves of the standards, the sugars peaking at $7.8 \mathrm{~min}$ and $10.0 \mathrm{~min}$ were referred to as monosaccharides and disaccharides, respectively. Disaccharides content of the control dough sharply reduced after fermentation probably due to the consumption by yeasts. Compared with the control, Jiu-niang dough showed a peak containing a large number of monosaccharides which was from the addition of Jiu-niang. However, the dough treated with Jiuniang showed a decrease of monosaccharides and an increase of disaccharides. Utilization of monosaccharides in preference by yeasts resulted in the decrease of monosaccharides. On the contrary, peak area of disaccharides for the Jiu-niang dough largely increased, from 13896.1 to 42171.5 (data not shown). The results showed that the increase of disaccharides was probably attributed to the hydrolysis of polysaccharides by the action of amylase in Jiu-niang. Monosaccharides and disaccharides released could be further used for the growth of yeasts, leading to the expansion of dough and the capacity to hold gas and the improvement of the quality of bakery products.

\subsection{Fresh bread characterization}

Jiu-niang fermented for $36 \mathrm{~h}$ was added at different amounts $(5 \%, 10 \%, 15 \%$ and $20 \%)$ into the dough for the further incorporation in bread making. Reducing sugar contents of different bread samples are given in Table 1. The addition of Jiu-niang significantly increased the reducing sugar content of bread in a concentration-dependent manner. This was probably due to amylase produced by Rhizopus oryzae during Jiu-niang fermentation. The presence of amylase hydrolyzed starch molecule into monosaccharide, leading to augmentation of reducing sugar content.

Specific volume is an important indicator to measure the quality of bread which reflects dough expansion and its capacity to hold gas. The results (Table 1) indicated that addition of Jiu-niang significantly $(P<0.05)$ increased the value of specific volume except the sample added with 5\% Jiu-niang. Jiu-niang is rich in reducing sugar, and can promote yeast growth during dough fermentation to generate a high amount of gas. It was also worth noting that the specific volume suddenly decreased when a large amount (20\%) of Jiu-niang was added into dough. This was because excessive amounts of protease resulted in hydrolysis of gluten, therefore destroying dough structure and decreasing gas holding capacity.

Chemical reactions that occur during baking, such as Maillard reactions and caramelization, cause browning and color differences of baked products. The color and flavor formed during baking are related to the reactions between reducing sugars and amino acids. ${ }^{25}$ The crust of Jiu-niang bread had significantly lower $L$ values and the values of $L$ decreased along. with the rising addition of Jiu-niang (Table 1). Increase in redness and decrease in yellowness were found for bread containing Jiu-niang. The darker color of Jiu-niang bread was attributed to its high content of reducing sugar which caused 
Table 1 Physical properties of bread containing different amounts of Jiu-niang ${ }^{a}$

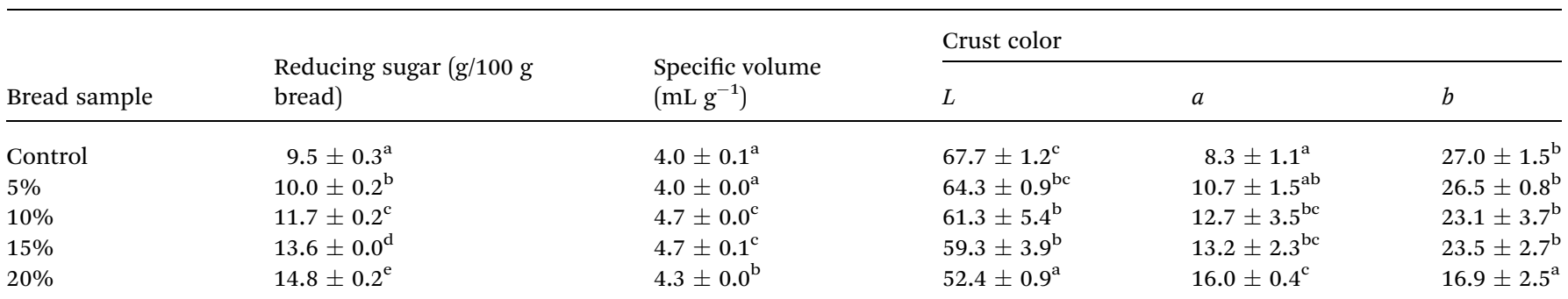

${ }^{a}$ Results are presented as the mean \pm standard deviation. Different small letters within a column represent that the values are significantly different at $P<0.05$.

a greater extent of Maillard reactions, thereby intensifying the crust color of final products.

\subsection{Texture profile analysis of bread during storage}

Hardness, springiness and cohesiveness are the three TPA attributes selected to evaluate the texture of bread in this experiment. Table 2 demonstrates the effects of Jiu-niang concentration and storage time and their interaction on the texture of bread. During 7 days of storage, the hardness gradually increased with increasing storage time both in the Jiuniang treated bread and the control bread. As was shown in Table 2, the effects of Jiu-niang concentration, storage time and their interaction on the value of hardness were significant $(P<$ $0.0001, P<0.0001$ and $P<0.0001$, respectively). Jiu-niang bread showed a lower hardness value and softer texture compared with the control at any time of the storage. The difference of hardness value was not significant of all bread samples at early stage of storage. However, the hardness value of Jiu-niang treated samples was significantly $(P<0.05)$ lower than that of the control as a function of time. The control sample had the highest hardness value which reached the maximum of $1317.58 \mathrm{~g}$ on the seventh day of storage. In addition, the value of hardness decreased at first and then increased as Jiu-niang level increased. Too much addition (20\%) could lead to a harder texture of bread which was probably due to large quantities of protease in Jiu-niang. Proper protease content was beneficial to dough preparation as proteins would be degraded into amino acids which were important precursors to form the flavor of bread. When the dough was added with $20 \%$ Jiu-niang, large amounts of protease would hydrolyze gluten, resulting to the collapse of dough and deteriorating the appearance and texture of final products. ${ }^{26} 10 \%$ was an appropriate addition level of Jiuniang since the bread had the lowest hardness and the highest specific volume (Table 1) values. Addition of $10 \%$ Jiu-niang reduced $50 \%$ crumb hardness compared with the control on the first day. In general, springiness and cohesiveness decreased as a function of time (Table 2).

Table 2 Effects of Jiu-niang concentration, storage time and their interaction on the texture of different bread samples ${ }^{a}$

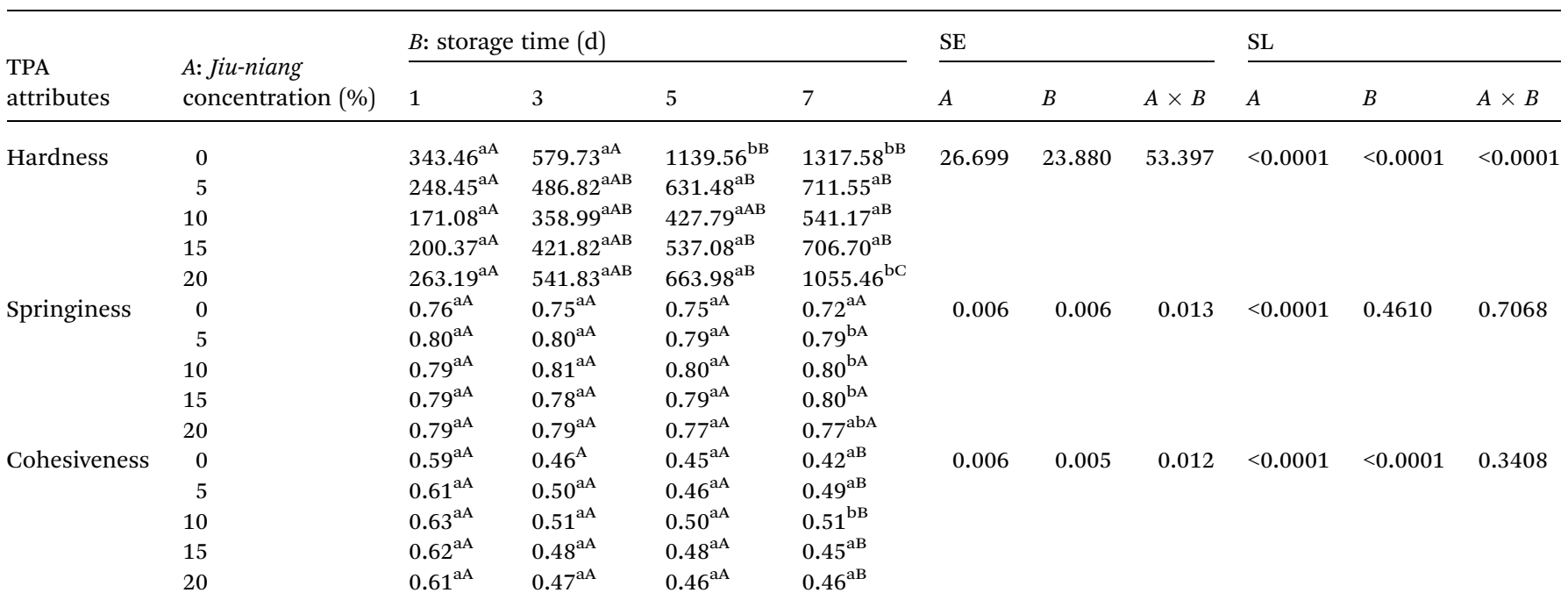

${ }^{a}$ Results are presented as the mean \pm standard deviation. For the same TPA attribute, values with the same small letter at the same storage time for different bread samples and with the same capital letter at different storage times of one bread are not significantly different at $P<0.05$. For the same TPA attribute, values with the same small letter at the same storage time for different bread samples and with the same capital letter at different storage times of one bread are not significantly different at $P<0.05$. SE: standard error of the mean. SL: least significant difference. 
The effects of Jiu-niang concentration and storage time on the value of springiness were significant $(P<0.0001, P<0.0001)$ whereas their interaction on springiness and cohesiveness were not. For Jiu-niang bread, the change of springiness during storage was not obvious. All bread samples displayed similar springiness and cohesiveness on the first day of storage. However, the results represented a sharp decrease in springiness and cohesiveness for the control sample at the end of storage which would influence consumer's satisfaction of bread. The lower hardness and higher cohesiveness and springiness leaded to a softer texture of bread.

Hardness is a negative indicator of bread textural changes during storage.$^{27}$ In contrast, cohesiveness, and springiness are normally seen as positive characters to evaluate bread quality. During storage time, these two attributes decreased because of the retrogradation of starch. Currently, amylases are frequently used in bread making. The activity of amylases in dough during fermentation and bread baking impacts several characteristics of bread, including specific volume, firmness and firming rate. ${ }^{28}$ The hardness of bread is one of the measures of the degree of bread staling. The increased bread softness due to addition of Jiu-niang may be attributed to the presence of amylase in the system. A part of starch molecules could be converted into monosaccharide and dextrin by the action of amylase that is present in Jiu-niang, and thus the long chain and molecular weight of starch was reduced. In such a pathway, the weakness of starch networks particularly the recrystallized amylopectin network was occurring, resulting in the reduction of bread hardness. ${ }^{3}$ Furthermore, the value of crumb hardness is generally linked to porosity. ${ }^{29}$ The reducing sugar produced through hydrolyzation was used by yeasts to generate a large amount of gas, which leaded to the high porosity and aeration of Jiu-niang bread and thus decreased the crumb hardness. ${ }^{30}$

\subsection{Moisture migration of bread during storage}

After baking, bread crumb showed a higher moisture content than crust which would lead to the redistribution and migration of water between bread crumb and crust. During the time of storage, moisture migrated from crumb to crust, resulted in the decrease of moisture content in bread crumb and the increase in bread crust. Fast moisture migration resulted in dehydration of the bread and leaded to the hardness of bread crumb. ${ }^{31}$ The results showed that the moisture migration rate of crumb augmented in the first few days and then decreased (Fig. 3). The moisture migration rate of bread crust displayed the similar change tendency. It was possible that water migrated quickly in the first few days and resulted in high values of moisture migration rate. The rate of crumb moisture reduction was relatively lower in Jiu-niang bread, especially the bread supplemented with $10 \%$ Jiu-niang. The results demonstrated that the rate of moisture migration (both crumb and crust) of the control bread was much faster. The addition of Jiu-niang could reduce the moisture migration from crumb to crust.

Moisture migration is one of the most important parameters to measure the degree of bread staling. ${ }^{32}$ It has been reported by Baik \& Chinachoti (2000) that water migrated between crumb

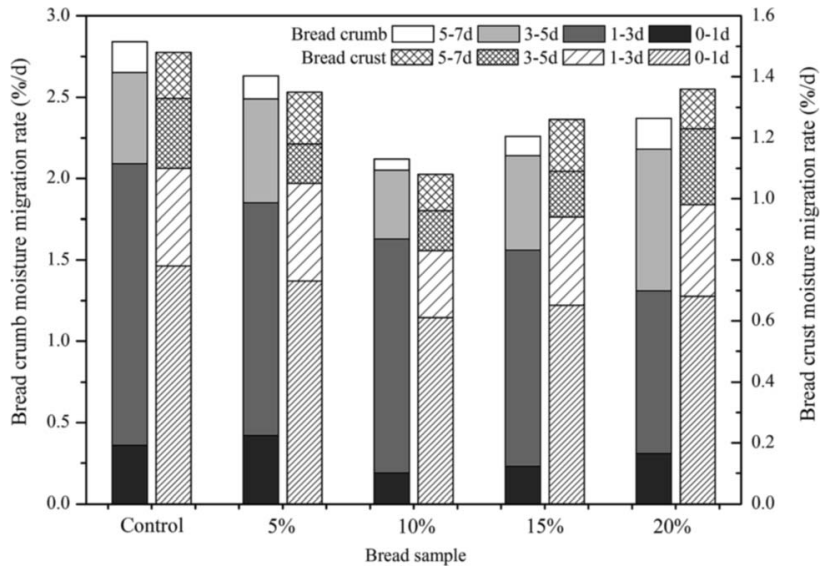

Fig. 3 Moisture migration of bread crumb and crust during storage of 7 days.

and crust was due to the moisture gradient. ${ }^{4}$ During storage time of bread, there was a redistribution of water when retrogradation of amylopectin occurred. Water migrated from crumb to crust and became immobilized, as more and more water moved into amylopectin crystallites. Amylases hydrolyzed starch granules into smaller molecules, dextrins for example. During bread baking, amylases had effects on starch to form branched chain polymer of dextrins to hold water and then decreased retrogradation of bread. ${ }^{1}$ Bread with Jiu-niang supplemented had less moisture loss in crumb and low moisture migration rate between crumb and crust, to a certain degree, decrease crystallization of starch.

\subsection{Proton distribution of bread during storage}

LF-NMR measurement is an effective method to show molecular mobility of small and dynamics molecules and crumb firming in bread during storage time. ${ }^{33} T_{2}$ relaxation time obtained by CPMG pulse sequence is a good representative of protons mobility. ${ }^{34} \mathrm{~A}$ longer $T_{2}$ relaxation time indicates a more freedom kind of proton. Three different proton populations (peaking at $\sim 0.5-0.8 \mathrm{~ms}, \sim 5-6 \mathrm{~ms}$ and $\sim 27-30 \mathrm{~ms}$ ) were obtained by CPMG pulse sequence (Table 3). Population B was regarded as the major fraction and accounted for $82 \%$ of total signal (data not shown). Population A and C encompassed approximately $12 \%$ and $6 \%$. The three peaks represented three diverse degrees of proton mobility. Population B was the most abundant which was probably referred to protons of free water in bread crumb. Li et al., (2015) also attributed this part to weakly bound or free water. ${ }^{35}$ However, besides the mobile $\mathrm{OH}$ protons of water, the exchangeable protons of starch and gluten constituted population B as well. ${ }^{36}$ The determination of different $T_{2}$ relaxation time was reported in similar products. Curti et al. (2014) investigated the molecular mobility of three gluten enriched breads and found three proton distributions $\left(T_{2 \mathrm{~A}} \sim 0.2 \mathrm{~ms}, T_{2 \mathrm{~B}}\right.$ $\sim 11 \mathrm{~ms}$ and $T_{2 \mathrm{C}}>20 \mathrm{~ms}$ ) which were attributed to rigid and exchanging protons of starch and gluten interacting with water molecules, more mobile and exchanging protons of starch, gluten and water and mobile protons of lipids, respectively. ${ }^{9}$ 
Table $3 T_{2}$ relaxation times and areas of proton distributions of bread crumb stored at $25^{\circ} \mathrm{C}$ for 7 days ${ }^{a}$

\begin{tabular}{|c|c|c|c|c|c|c|c|}
\hline \multirow{2}{*}{$\begin{array}{l}\text { Bread } \\
\text { sample }\end{array}$} & \multirow{2}{*}{$\begin{array}{l}\text { Storage } \\
\text { time (d) }\end{array}$} & \multicolumn{2}{|l|}{ Population A } & \multicolumn{2}{|l|}{ Population B } & \multicolumn{2}{|l|}{ Population C } \\
\hline & & $T_{2}(\mathrm{~ms})$ & Area & $T_{2}(\mathrm{~ms})$ & Area & $T_{2}(\mathrm{~ms})$ & Area \\
\hline & 3 & $0.7 \pm 0.0^{\mathrm{aA}}$ & $1458.0 \pm 31.3^{\mathrm{bA}}$ & $6.1 \pm 0.1^{\mathrm{dA}}$ & $10071.5 \pm 35.5^{\mathrm{aB}}$ & $30.6 \pm 0.8^{\mathrm{aB}}$ & $639.5 \pm 44.4^{\mathrm{aA}}$ \\
\hline & 5 & $0.6 \pm 0.1^{\mathrm{aA}}$ & $1491.9 \pm 125.5^{\mathrm{aA}}$ & $6.1 \pm 0.1^{\mathrm{dA}}$ & $9954.9 \pm 105.7^{\mathrm{aB}}$ & $29.1 \pm 1.7^{\mathrm{aAB}}$ & $710.9 \pm 93.4^{\mathrm{aAB}}$ \\
\hline & 7 & $0.8 \pm 0.1^{\mathrm{abB}}$ & $1411.0 \pm 20.7^{\mathrm{bcA}}$ & $6.2 \pm 0.1^{\mathrm{dA}}$ & $8921.5 \pm 829.1^{\mathrm{aA}}$ & $30.23 \pm 1.1^{\mathrm{aB}}$ & $756.0 \pm 68.7^{\mathrm{bAB}}$ \\
\hline & 5 & $0.7 \pm 0.0^{\mathrm{abA}}$ & $1422.1 \pm 5.6^{\mathrm{aA}}$ & $5.8 \pm 0.0^{\mathrm{cAB}}$ & $9998.5 \pm 35.0^{\mathrm{aA}}$ & $29.8 \pm 0.7^{\mathrm{aA}}$ & $672.7 \pm 30.1^{\mathrm{aA}}$ \\
\hline & 7 & $0.8 \pm 0.1^{\mathrm{aA}}$ & $1449.2 \pm 65.5^{\mathrm{cAB}}$ & $5.7 \pm 0.1^{\mathrm{cA}}$ & $9784.5 \pm 109.2^{\mathrm{bA}}$ & $30.1 \pm 0.6^{\mathrm{aA}}$ & $655.3 \pm 9.7^{\mathrm{abA}}$ \\
\hline \multirow[t]{4}{*}{$10 \%$} & 1 & $0.7 \pm 0.0^{\mathrm{cA}}$ & $1487.2 \pm 44.5^{\mathrm{bA}}$ & $5.6 \pm 0.1^{\mathrm{bA}}$ & $9915.7 \pm 57.6^{\mathrm{aA}}$ & $28.1 \pm 0.9^{\mathrm{aA}}$ & $812.5 \pm 28.3^{\mathrm{aB}}$ \\
\hline & 3 & $0.8 \pm 0.0^{\mathrm{bcAB}}$ & $1454.1 \pm 112.8^{\mathrm{bA}}$ & $5.6 \pm 0.1^{\mathrm{bA}}$ & $9996.0 \pm 261.8^{\mathrm{aA}}$ & $29.0 \pm 0.2^{\mathrm{aA}}$ & $773.4 \pm 82.2^{\mathrm{bAB}}$ \\
\hline & 5 & $0.8 \pm 0.0^{\mathrm{bcB}}$ & $1370.8 \pm 61.0^{\mathrm{aA}}$ & $5.5 \pm 0.1^{\mathrm{bA}}$ & $9807.1 \pm 217.0^{\mathrm{aA}}$ & $29.7 \pm 2.5^{\mathrm{aA}}$ & $687.5 \pm 49.9^{\mathrm{aA}}$ \\
\hline & 7 & $0.8 \pm 0.0^{\mathrm{abB}}$ & $1375.4 \pm 56.0^{\mathrm{bcA}}$ & $5.4 \pm 0.1^{\mathrm{bA}}$ & $9804.9 \pm 50.0^{\mathrm{bA}}$ & $29.7 \pm 2.6^{\mathrm{aA}}$ & $700.7 \pm 47.9^{\mathrm{abA}}$ \\
\hline \multirow[t]{4}{*}{$20 \%$} & 1 & $0.8 \pm 0.0^{\mathrm{dA}}$ & $1411.9 \pm 12.5^{\mathrm{aB}}$ & $5.4 \pm 0.0^{\mathrm{aD}}$ & $9948.0 \pm 19.6^{\mathrm{aB}}$ & $27.6 \pm 0.2^{\mathrm{aA}}$ & $785.9 \pm 0.8^{\mathrm{aB}}$ \\
\hline & 3 & $0.9 \pm 0.0^{\mathrm{dB}}$ & $1267.3 \pm 1.1^{\mathrm{aA}}$ & $5.3 \pm 0.0^{\mathrm{aC}}$ & $9712.0 \pm 25.9^{\mathrm{aA}}$ & $28.6 \pm 0.3^{\mathrm{aA}}$ & $663.5 \pm 2.1^{\mathrm{abAB}}$ \\
\hline & 5 & $0.8 \pm 0.1^{\mathrm{bcAB}}$ & $1327.6 \pm 117.9^{\mathrm{aAB}}$ & $5.3 \pm 0.1^{\mathrm{aB}}$ & $9930.2 \pm 110.7^{\mathrm{aB}}$ & $27.0 \pm 1.5^{\mathrm{aA}}$ & $741.2 \pm 156.8^{\mathrm{aAB}}$ \\
\hline & 7 & $1.0 \pm 0.1^{\mathrm{bB}}$ & $1251.0 \pm 14.9^{\mathrm{aA}}$ & $5.2 \pm 0.0^{\mathrm{aA}}$ & $9721.3 \pm 113.1^{\mathrm{bA}}$ & $29.5 \pm 3.0^{\mathrm{aA}}$ & $610.1 \pm 66.5^{\mathrm{aA}}$ \\
\hline
\end{tabular}

${ }^{a}$ Results are presented as the mean \pm standard deviation. Values with the same small letter at the same storage time for different bread samples and with the same capital letter at different storage times of one bread are not significantly different at $P<0.05$.

Bosmans et al., (2013) investigated water dynamics and proton mobility in starch and gluten of bread crumb. ${ }^{37}$ However, four $T_{2}$ relaxation times (peaking at $\sim 0.5 \mathrm{~ms}, \sim 2 \mathrm{~ms}, \sim 15 \mathrm{~ms}$ and $\sim 100 \mathrm{~ms}$ ) were observed by CPMG sequence. The $T_{2}$ relaxation times at $0.5 \mathrm{~ms}$ and $2 \mathrm{~ms}$ were represented rigid protons from starch and gluten in little contact with water and exchanging protons of confined water, starch and gluten. The two more mobile populations were attributed to exchanging protons of mobile water, starch and gluten and lipid protons. On the basis of these reports above, the three populations in this experiment were reasonably proposed. Population B was assigned to mobile and exchangeable protons of water, starch and gluten. Population $\mathrm{C}$, the most mobile proton, was assumed to be protons of lipid in bread. The population A had a very short $T_{2}$ relaxation time could be considered as both rigid and exchangeable protons of starch and gluten in contact with water molecules.

The data for $T_{2}$ relaxation times of protons distributions stored at $25^{\circ} \mathrm{C}$ of bread crumb are shown in Table 3. During the storage, both the peak area and the average peak position of population B is dramatically reduced, suggesting that the reduction of mobile and exchangeable protons of starch, gluten and water, as well as the declination of water mobility. Bread with Jiu-niang added had a relatively shorter relaxation time of peak B and the peak time became shorter as the addition of Jiu-niang increased. The high soluble solids content of Jiu-niang increased the viscosity of dough and then decreased the mobility of water, leading to the shorter $T_{2}$ relaxation time of bread. Moreover, the area of population B decreased much faster in control bread than Jiu-niang treated bread. The peak strength of population B changed during storage period as the protons with a large degree of mobility could move to places where they fixed more tightly. Bread added with $10 \%$ Jiu-niang had minimal changes in population B. On the contrary, after 7 days of storage, the peak area of the control was down to 8921.5, which was the lowest among the other samples.

The area of population A, containing both rigid and exchangeable protons of starch and gluten in contact with water molecules, was initially lower in Jiu-niang treated bread. In addition, the area of population A decreased as the concentration of Jiu-niang augmented. These differences showed that the addition of Jiu-niang resulted in hydrolysis of starch molecules and finally reduced signal intensity of population A. There was a significant decrease in the area of population A of the control at the end of the storage. Meanwhile, Jiu-niang bread, especially the dough treated with $10 \%$ Jiu-niang, showed no obvious changes in population $\mathrm{A}$. The retrogradation of amylopectin resulted in a shift of the protons of this part to form crystalline structures with shorter relaxation time, shown as a decrease area of population A. $^{37}$ Jiu-niang effectively reduced the shift in protons to lower mobility and the formation of amylopectin crystals. During the storage, Jiu-niang bread showed a lower moisture migration rate and less water loss (Fig. 3) in crumb owing to the capacity to hold water of starch network. At a molecular level, a smaller decrease in population A indicated that only a small amount of protons shifted to population with shorter relaxation time and formed amylopectin crystals during the storage. The prevention of amylopectin crystal formation leaded to a less rigid, continuous and crystalline starch network with water included. ${ }^{38}$ These differences were possible due to the action of amylase. The anti-staling efficiency of amylases in 
bread can be correlated to the limitation degrees of the formation and the strength of the permanent amylopectin network, as well as the water immobilization, thus, controlled starch retrogradation and bread staling. ${ }^{3}$

\subsection{Physico-chemical properties of Jiu-niang}

The changes of $\mathrm{pH}$ and soluble solids content (SSC) as a function of fermentation time are shown in Fig. 4a. The value of $\mathrm{pH}$ gradually reduced from 3.7 to 3.3 during fermentation. The production of acids such as lactic acid by Rhizopus oryzae caused the acidification of the medium. The SSC quickly increased in early fermentation period and then trended to be stable from 18 to $54 \mathrm{~h}$. The value of SSC reached the maximum of $39.8 \%$ at $36 \mathrm{~h}$. The soluble solids in Jiu-niang were mainly composed of reducing sugars and some other ingredients such as acids, vitamins and minerals. In the fermentation process of Jiu-niang, Rhizopus oryzae plays an important role in the saccharification of starch. The production of reducing sugars is consumed by yeasts for their growth. This consumption will lead to release of gas. $^{39}$

Bread quality was improved probably due to enzymes produced during solid-state fermentation using glutinous rice as a nutrient source. $\alpha$-Amylase, protease and lipase were three
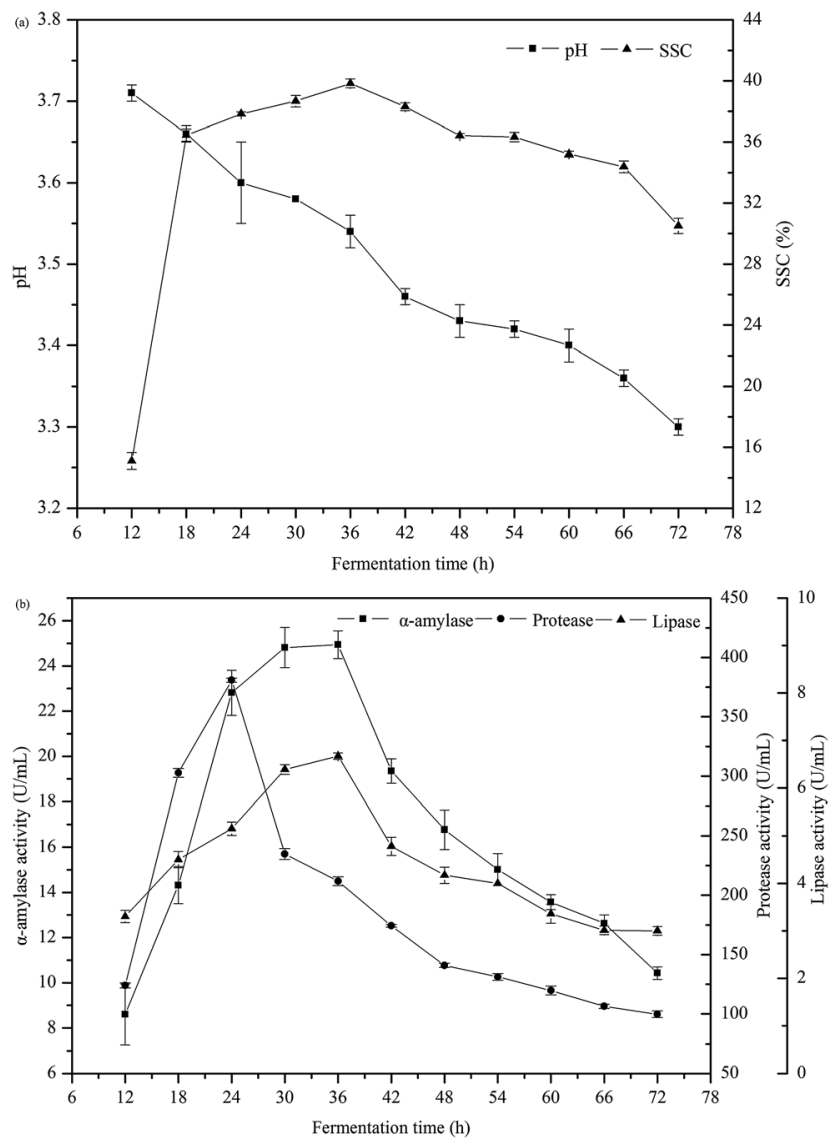

Fig. 4 (a) Changes of $\mathrm{pH}$ and soluble solids content (SSC) in Jiu-niang as a function of fermentation time. (b) Principal enzymes activities in Jiu-niang as a function of fermentation time. principal enzymes produced by Rhizopus oryzae. Results of these enzymes activities can be found in Fig. 4b. The activity of $\alpha$-amylase increased quickly from 12 to $36 \mathrm{~h}$ and then decreased. The value reached the maximum at $36 \mathrm{~h}$ of $24.9 \mathrm{U}$ $\mathrm{mL}^{-1}$. The $\alpha$-amylase positively acted on bread texture by hydrolyzing starch into low molecular weight dextrins and then interfered with the amylopectin retrogradation occurring during bread storage. The $\alpha$-amylase in Jiu-niang had an effect on the development of bread structure, leading to a softer, more springy and more cohesive product. Similar to $\alpha$-amylase, the maximum value of lipase activity reached at $36 \mathrm{~h}$ of $6.7 \mathrm{U} \mathrm{mL}^{-1}$. For the protease, the activity rose sharply until reached the highest value of $380.9 \mathrm{U} \mathrm{mL}^{-1}$ and then substantially decreased. Enzyme activity was closely related to the growth situation of mould. Rhizopus oryzae grew rapidly at the beginning of the fermentation, resulting in large production of enzymes. There was then a decline in enzyme activity which indicated that the amount of moulds began to decrease. High enzyme activity of protease and too much acidification of dough caused degradation of gluten and hindered the formation of gluten network. ${ }^{40}$ According to the results above, the optimum addition amount found was $10 \%$.

\section{Conclusions}

Jiu-niang could be applied as a natural enzyme cocktail in bread baking which influenced several characteristics and offered a good overall quality of bread. Addition of Jiu-niang obviously increased specific volume of bread, reduced bread hardness and moisture migration from crumb to crust. At a molecular level, small decreases in population A (both rigid and exchanging protons of starch and gluten in contact with water molecules) and B (mobile and exchangeable protons of water, starch and gluten) of Jiu-niang bread were observed by LF-NMR, which indicated that only a small amount of protons shifted to population with shorter relaxation time and formed amylopectin crystals during the storage. In addition, the optimum addition amount of Jiu-niang was $10 \%$ as highest specific volume, lowest hardness and minimum changes in moisture migration and proton mobility were detected for bread supplemented with $10 \%$ Jiu-niang.

\section{Funding information}

This project was funded by the National High Technology Research and Development Program of China (863 Program, 2011AA100903), Key Projects in the National Science \& Technology Pillar Program (2013BAD18B01-4) and National Undergraduates Innovating Experimentation Project (201410307054).

\section{Conflict of interest}

The authors declare that they have no competing interests. 


\section{Abbreviations}

LF-NMR Low-field nuclear magnetic resonance

HPLC High performance liquid chromatography

SDS- $\quad$ Sodium dodecyl sulfate polyacrylamide gel

PAGE electrophoresis

TPA Texture profile analysis

SSC Soluble solids content

\section{Acknowledgements}

The authors would like to thank Jiangsu Collaborative Innovation Center of Meat Production and Processing, Quality and Safety Control for some technical supports.

\section{References}

1 W. Lin and D. R. Lineback, Starch/Staerke, 1990, 42, 385-394.

2 L. M. Hallberg and P. Chinachoti, J. Food Sci., 2002, 67, 10921096.

3 H. Goesaert, L. Slade, H. Levine and J. A. Delcour, J. Cereal Sci., 2009, 50, 345-352.

4 M. Y. Baik and P. Chinachoti, Cereal Chem., 2000, 77, 484488.

5 G. M. Bosmans, B. Lagrain, N. Ooms, E. Fierens and J. A. Delcour, Food Chem., 2014, 165, 149-156.

6 L. Slade and H. Levine, Crit. Rev. Food Sci. Nutr., 1991, 30, 115-360.

7 A. Imberty and S. Perez, Biopolymers, 1988, 27, 1205-1221.

8 E. Vittadini and Y. Vodovotz, J. Food Sci., 2003, 68, 20222027.

9 E. Curti, E. Carini, G. Tribuzio and E. Vittadini, LWT-Food Sci. Technol., 2014, 59, 418-425.

10 M. L. Martin and R. C. Hoseney, Cereal Chem., 1991, 68, 503507.

11 J. H. Kim, T. Maeda and N. Morita, Food Res. Int., 2006, 39, 117-126.

12 J. K. Purhagen, M. E. Sjöö and A. C. Eliasson, Food Hydrocolloids, 2011, 25, 1656-1666.

13 S. P. Cauvain and N. Chamberlain, J. Cereal Sci., 1988, 8, 239-248.

14 T. Li, C. Tu, X. Rui, Y. Gao, W. Li, K. Wang, Y. Xiao and M. Dong, J. Agric. Food Chem., 2015, 63, 3261-3270.

15 B. Chen, Q. Wu and Y. Xu, Int. J. Food Microbiol., 2014, 179, 80-84.

16 J. Zhong, X. Ye, Z. Fang, G. Xie, N. Liao, J. Shu and D. Liu, Food Control, 2012, 28, 151-156.
17 F. Zhu, R. Sakulnak and S. N. Wang, Food Chem., 2016, 194, 1217-1223.

18 A. A. L. Tribst and M. Cristianini, Innovative Food Sci. Emerging Technol., 2012, 13, 107-111.

19 D. Senyay-Oncel, A. Kazan and O. Yesil-Celiktas, Biochem. Eng. J., 2014, 92, 83-89.

20 J. Yang, X. Ma, Z. Zhang, B. Chen, S. Li and G. Wang, Biotechnol. Adv., 2010, 28, 644-650.

21 J. Y. Lim, J. J. Kim, D. S. Lee, G. H. Kim and J. Y. Shim, Food Chem., 2010, 120, 255-260.

22 C. Wu, R. Liu, W. Huang, P. Rayas-Duarte, F. Wang and Y. Yao, J. Cereal Sci., 2012, 56, 127-133.

23 H. Tang, S. He, F. Peng, R. Wang, Q. Li and Y. Ma, RSC Adv., 2016, 6, 102617-102625.

24 P. Wang, Z. Jin and X. Xu, Trends Food Sci. Technol., 2015, 46, 189-198.

25 M. Heitmann, E. Zannini and E. K. Arendt, J. Cereal Sci., 2015, 63, 49-56.

26 A. Matsuo, K. Sato, E. Y. Park, Y. Nakamura and K. Ohtsuki, J. Funct. Foods, 2012, 4, 513-519.

27 A. S. Szczesniak, J. Food Sci., 1963, 28, 385-389.

28 B. Lagrain, P. Leman, H. Goesaert and J. A. Delcour, Food Res. Int., 2008, 41, 819-827.

29 H. Chanvrier, E. Jakubczyk, E. Gondek and J. Gumy, Innovative Food Sci. Emerging Technol., 2014, 24, 61-68.

30 S. Hug-Iten, F. Escher and B. Conde-Petit, Cereal Chem., 2003, 80, 654-661.

31 L. Piazza and P. Masi, Cereal Chem., 1995, 72, 320-325.

32 D. E. Rogers, K. J. Zeleznak, C. S. Lai and R. C. Hoseney, Cereal Chem., 1988, 65, 398-401.

33 G. M. Bosmans, B. Lagrain, J. L. Deleu, E. Fierens, B. P. Hills and J. A. Delcour, J. Agric. Food Chem., 2012, 60, 5461-5470.

34 S. G. Choi and W. L. Kerr, LWT-Food Sci. Technol., 2003, 36, 105-112.

35 Z. Li, C. Deng, H. Li, C. Liu and K. Bian, Food Chem., 2015, 179, 257-262.

36 A. S. Hager, G. M. Bosmans and J. A. Delcour, J. Agric. Food Chem., 2014, 62, 5682-5689.

37 G. M. Bosmans, B. Lagrain, N. Ooms, E. Fierens and J. A. Delcour, J. Agric. Food Chem., 2013, 61, 4646-4654.

38 G. M. Bosmans, B. Lagrain, E. Fierens and J. A. Delcour, Food Chem., 2013, 61, 6525-6532.

39 A. E. León, E. Durán and C. Benedito de Barber, J. Agric. Food Chem., 2002, 50, 1416-1419.

40 C. Thiele, S. Grass and M. Ganzle, J. Agric. Food Chem., 2004, 52, 1307-1314. 